\title{
The Growing Up Use of Pesticides in Brazil Compared with the World
}

\author{
Eduardo José Azevedo Corrêa* \\ Biologist, Researcher at Company of Agricultural Research of the Minas Gerais State (EPAMIG), Experimental Field of Pitangui, Pitangui City, Minas Gerais \\ State, Brazil
}

*Corresponding author: Eduardo José Azevedo Corrêa, Biologist, Researcher at Company of Agricultural Research of the Minas Gerais State (EPAMIG), Experimental Field of Pitangui, Postal Box 43, Pitangui City, Minas Gerais State, Postal Code 35650-000, Brazil.

Received Date: May 14, 2020

Published Date: May 29, 2020

\begin{abstract}
The world population are growing faster, and the need for food to suppling this necessity too. Until now the main strategy to plague control is the use of synthetic pesticides like insecticides, herbicides etc. Brazil is one of most important users of pesticides around the world. With high biodiversity of species, these spread of pesticides across all Brazilian's ecosystems could cause a great damage to species and so the species extinction. In this scenario, it is important and urgent to develop new ecofriendly technology to food production in Brazil.
\end{abstract}

Keywords: Pesticides; Food production; Brazil

\section{Introduction}

It is not a surprise that a number of world citizens are growing faster and faster, at 2010 we are at near of the 7 billion of human being and this year we have almost one billion more people following the Malthus' curve [1].

With higher the population more food is necessary. It is known that the food requirement by a person change with age and some other individual parameters, it is estimated that a minimum energy requirement is about 1690 - $1650 \mathrm{kcals} /$ person/day [2]. Considering this numbers, we need and amount of food to provide 11.830.000.000.000 kcals every day in food to feed all person around the world. It is a big amount of food and energy.

With this great challenge, all the nations around the world and your government have been faced by big problem. How to produce food in quantity and quality without degrade the ecosystems and extinct the species and your habitats.

This mini review is based on FAOSTAT data and shows how faster are the increase in pesticide usage at Brazil compared with the world. The FAOSTAT data show a high use of pesticides around the world, the only places that are pesticides free in world are Greenland and Antarctic continent. In the other places the pesticides usage is spreading fast and fast, in average the use of pesticide in world is 6.028.123 tones (Figure 1), with the Brazil occupying the third place with 360.000 tones in pesticide use in agriculture.

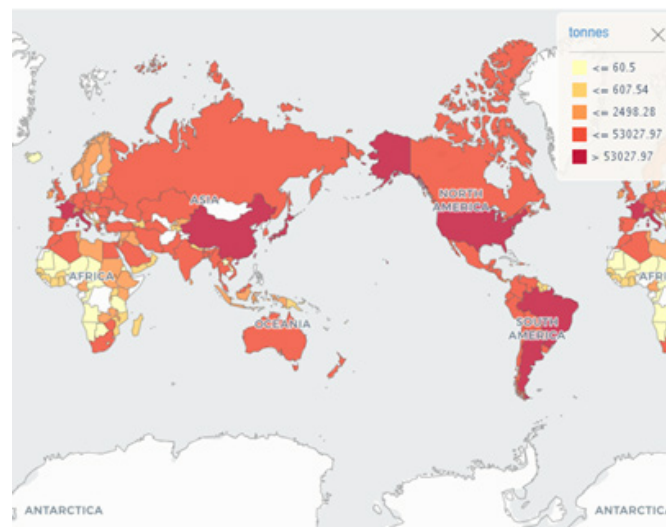

Figure 1: Pesticides usage by country in Tones [1]. 


\section{Pesticides Usage Growing in Brazil}

In this Mini review we briefly point how faster the use of pesticides are growing in agriculture from Brazil, I here use Open data from FAO [3] and R programming analysis. The total pesticide usage is growing faster in Brazil, mainly promoted by the herbicides and insecticides (Figure 2).

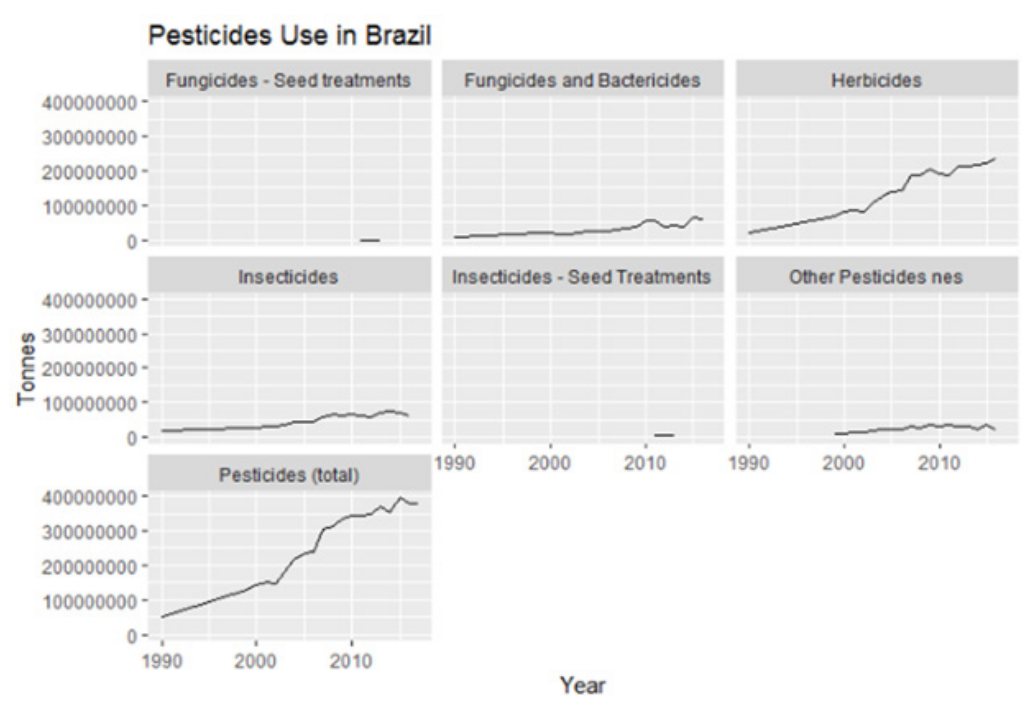

Figure 2: Report the increasing of pesticides types in Brazil during the time.

\section{Conclusion}

The data clearly shows that is urgent necessary to develop other plague control and crop healthy strategy, the increasing in the use of pesticides around the world specially in Brazil are leading us to turn ours lands a toxic place to live. In this sense the development of new kinds of technologies for food production like agroecology, agroforests, the syntropy of Ernst Gotsch, botanical insecticides, organic production and permaculture emerge as a signal of hope to a production of food healthier to supply these increasing food demand.

\section{Acknowledgement}

None.

\section{Conflict of Interest}

No conflict of interest.

\section{References}

1. Worldometer Info (2020) Current World Population.

2. FAO (2008) FAO Methodology for the Measurement of Food Deprivation: Updating the minimum dietary energy requirements, Rome.

3. FAO (2020) Pesticides Use. 